\title{
Flattening the curve in COVID-19 using personalised protective equipment: lessons from air pollution
}

\author{
Sanjay Rajagopalan (10 , ${ }^{1}$ Sui Huang, ${ }^{2}$ Robert D Brook ${ }^{3}$
}

\section{INTRODUCTION}

COVID-19 is a massive global economic and health calamity causing social and economic disruption at an unprecedented scale. Ironically, this large-scale disruption in anthropogenic activity has also fueled a massive downturn in consumption of fossil fuels and global reduction in air pollution. Indeed, it is widely speculated that current reductions in acute coronary syndrome admissions noted globally may relate to reduction in air pollution level, given the well-known relationship between reductions in air pollution levels and cardiovascular events. The ominously opposing trajectories, decrease in air pollutionrelated mortality and surge in COVID-19 deaths also reveal the eerie similarities in the flurry of public discourse regarding the utility of personalised protective equipment (PPE) to prevent exposure among the public.

Prior to the COVID-19 epidemic, there has been a vigorous debate about the efficacy of PPEs, including N95 respirators and masks, in protecting the public against air pollution risk (which is for the most part cardiovascular) and 'flattening' the shape of the air pollution exposure response curve. ${ }^{1}$ Unfortunately for air pollution, there has been limited guidance for the public in terms of efficacious personal interventions. Given the large burden of disease attributable to both air pollution and now COVID-19, the public deserves rapid dissemination and adoption of personal-level strategies to prevent untoward health outcomes.

Central to a public health approach in minimising spread among the general public is to mitigate risk of exposures, not only to COVID-19 cases but also to asymptomatic carriers who may harbour the virus and thus pose a significant health risk to others. This at the moment seems

\footnotetext{
'University Hospitals, Harrington Heart and Vascular Institute, Case Western Reserve University, Cleveland, Ohio, USA

${ }^{2}$ Institute of Systems Biology, Seattle, Washington, USA ${ }^{3}$ Cardiovascular Medicine, University of Michigan, Ann Arbor, Michigan, USA
}

Correspondence to Dr Sanjay Rajagopalan, Case Western Reserve University Hospital, Cleveland, $\mathrm{OH}$ 44106, USA; sxr647@case.edu to be a larger problem, given the fact that widespread testing is unavailable. While the efficacy of governmental lockdowns to minimise widespread dissemination of the virus to protect the public is highly effective in preventing spread at least in the short term, emerging data from countries such as China, Japan and South Korea suggest that other measures could also have contributed in reducing the spread. For instance, in many of these countries, the use of masks of all types was widespread prior to severe acute respiratory syndrome (SARS)-CoV2, and it is culturally and socially acceptable for the public to wear masks.

Citing lack of evidence, the Centers for Disease Control and Prevention (CDC) initially did not recommend the use of any face mask in any out of workplace setting. On 3 April 2020, citing 'new evidence', the CDC recommended wearing cloth face coverings in public settings. This is ironic because many CDC-recommended activities such as social distancing and handwashing also completely lack high levels of evidence to prevent pandemics. They were promoted because they are logical and are low/no-cost measures. While wearing a mask may not necessarily eliminate healthy people on the street from getting sick and does not replace important measures such as handwashing or social distancing, it may be considerably better than doing nothing. While studies reveal the challenge of establishing a clear benefit for handwashing, surface desensitisation, social distancing or of wearing masks, the absence of evidence is indeed not equivalent to evidence of absence.

Human corona viruses are typically about $125 \mathrm{~nm}$ but are often expelled as part of droplets that range from hundreds of microns down to about 10 microns. The critical size of the so-called large 'droplets' is a function of many physical parameters, such as relative humidity, the ambient air velocity and air temperature, while the trajectory and deposition of these droplets depend on the size and velocity of these particles when discharged from a patient or carrier. Previous modelling studies have suggested that large particles of $>100$ micron can reach distances as far as $6 \mathrm{ft}$ (the recommended gap for social distancing), when ejected via coughing or sneezing, but simple face masks could be effective with these larger particles (figure 1). In contrast, smaller particles of $<10$ micron can be carried for longer distances. The droplets of a typical cough expulsion have a wide size distribution, but recent studies using laser particle size analysers seem to suggest that the majority of particles are actually substantially larger than 50 microns with evidence of both unimodal and bimodal distribution of particles. $^{23}$ However, many studies have shown that there are substantial numbers of particles less than 2.5 micron $\left(\mathrm{PM}_{2.5}\right)$ which contribute very little to the overall mass but could potentially contribute to viral dissemination. This situation is analogous to air pollution where the $\mathrm{PM}_{2.5}$ and ultrafine particles contribute significantly to particle number but only to a small fraction of the overall mass, but, owing to their deposition into the distal airway/alveoli, may exert systemic effects, including on the cardiovascular system. ${ }^{1}$ In the case of SARS-CoV2, although a number of aspects of biology are unknown, a closer examination of several issues may convince most that it may be targetable using a simple mask intervention.

N95 respirators, widely touted as likely highly effective in reducing exposure to SARS-COV2, have only been validated for usage during occupational settings, with very few specifically validated to provide protection even against ambient $\mathrm{PM}_{2.5}$, let alone infectious agents like SARS-CoV2. Moreover, it is widely recognised that N95 respirators made by different manufacturers have different performance efficiencies below the 0.3 micron range that are dependent on user fit and other ambient conditions. N95 respirators are uncomfortable and cannot be worn for more than a few hours at a time and are not going to be available for use by the lay public, given current supply chain issues and cost. In contrast, inexpensive face masks, such as procedural (surgical masks) or others made from cloth, cotton or gauze, are widely available, can be worn for long periods successfully, and have been historically dismissed both for protection against $\mathrm{PM}_{2.5}$ and viral infections as they are presumed to be ineffective in reducing exposure to particles of 2.5 micron. While it is true that the number of studies that have compared N95 masks with surgical or cloth masks in the context of air pollution and viral infections is limited, it is untrue that there is no evidence. ${ }^{45}$ In a study in mannequins, disposable surgical masks were more effective than cloth masks, 


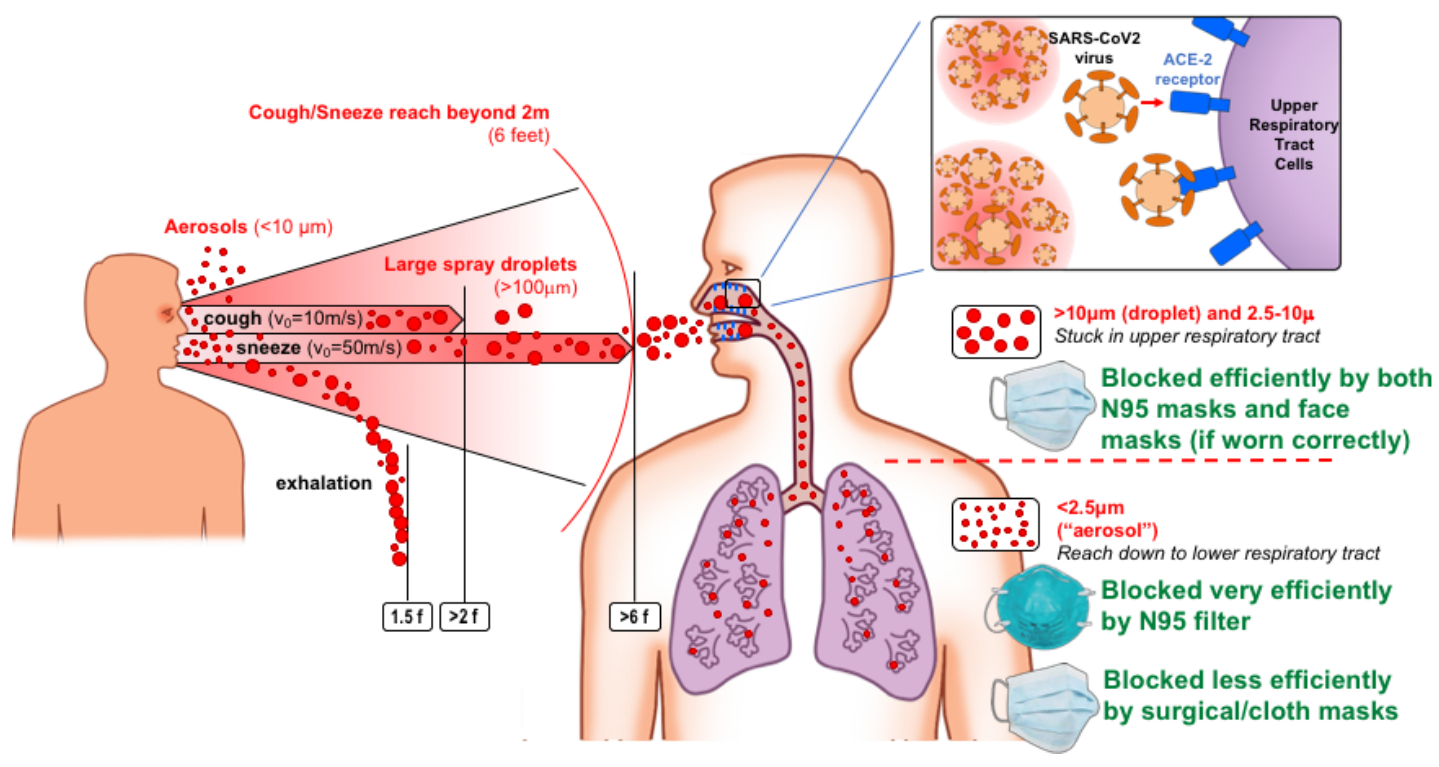

Figure 1 Size distribution of particles, hypothetical trajectories, deposition into the respiratory tract and the impact of personal protective equipment such as face masks and N95 filters. The inset depicts binding of the SARS CoV-2 to the ACE-2 recepto in the upper respiratory tract. SARS, severe acute respiratory syndrome.

but N95 respirators were the most effective in removing air particles. Cloth mask performance, although unpredictable in some cases, reduced particles by $57 \% .^{6}$ In a study in Indonesia, nine different masks were compared. Surgical masks were the only class of mask to significantly decrease $\mathrm{PM}_{2.5}$, although they had a large performance range and did not improve $\mathrm{PM}_{25}$ exposure in all subjects. ${ }^{7}$ This is to be expected, as a number of factors including facial seal are important determinants of efficacy of surgical masks. In another study from Europe comparing homemade cloth masks and surgical masks with N95 respirators in volunteers exposed mostly to particles in the ultrafine range $(<0.1$ micron), generated by lit candles, both inward protection and outward protection (protection from transmitting to the environment) were tested during both short term (few minutes) and over several hours. ${ }^{5}$ The results confirmed the superior efficacy of N95 respirators, but what was striking was the efficacy of surgical masks and homemade masks in reducing particle concentrations by 4-fold and 3-fold, respectively (compared with 100 -fold by the N95 mask). ${ }^{5}$ It is well known that the efficacy of masks for larger particles, particularly in the droplet range, likely the most important societal transmission mode of COVID, is substantially higher. Thus, the evidence supports the efficacy for a simple mask type intervention that may be particularly apt for the protection of caregivers not involved with direct patient care and also for the public at large, particularly in social situations that brings them in close proximity to others such as in grocery stores and restaurants.

Technically, one could quantify by how much the threefold to fourfold reduction of droplets achieved by masks may contribute to a reduction in SARS-CoV2 payload and reproduction rates, but unfortunately, this type of mathematical exercise would require a priori knowledge of a number of factors starting with the infectious load and the distribution of viral particles in large versus smaller particles, which are currently unavailable. However, a number of aspects relevant to SARS-CoV2 biology could be helpful in circumventing these limitations in understanding. Current testing for SARS-CoV2 suggests that the virus is present in large numbers in the upper respiratory tract. The receptor for SARS-CoV2 (ACE-2) is also highly expressed in the nasal epithelium and upper respiratory tract (figure 1 ). ${ }^{8}$ Given that the upper respiratory tract is the major site for SARS-Cov-2 replication and likely entry, wearing simple face masks which exert a barrier function in blocking not only large projectile droplets but also, to a lesser extent, smaller aerosols of $<10$ micron, may substantially reduce the replication rate. Thus, used in combination with other measures, a simple face mask intervention may result in further flattening of the 'curve'. The lessons learnt from COVID-19 could be leveraged to reduce air pollution-related cardiovascular mortality and morbidity once this current impasse from the virus lifts, the inevitable resumption of anthropogenic activity and related fossil fuel consumption at least in the short term.

Correction notice Since the online publication of this article, the authors noticed that 'Sanjay Rajagopalan' was incorrectly spelt as 'Sanjay Rajagopaian'. This error has been corrected.

Contributors SR drafted the manuscript. SH and RDB provided critical revisions.

Funding The authors have not declared a specific grant for this research from any funding agency in the public, commercial or not-for-profit sectors.

Competing interests None declared.

Patient and public involvement Patients and/or the public were not involved in the design, or conduct, or reporting, or dissemination plans of this research.

Patient consent for publication Not required.

Provenance and peer review Not commissioned; externally peer reviewed.

\section{(อ) OPEN ACCESS}

Open access This is an open access article distributed in accordance with the Creative Commons Attribution Non Commercial (CC BY-NC 4.0) license, which permits others to distribute, remix, adapt, build upon this work non-commercially, and license their derivative works on different terms, provided the original work is properly cited, appropriate credit is given, any changes made indicated, and the use is non-commercial. See: http:// creativecommons.org/licenses/by-nc/4.0/.

(C) Author(s) (or their employer(s)) 2020. Re-use permitted under CC BY-NC. No commercial re-use. See rights and permissions. Published by BMJ. 


\section{Editorial}

To cite Rajagopalan S, Huang S, Brook RD. Heart 2020;106:1286-1288.

Published Online First 11 May 2020

Heart 2020;106:1286-1288.

doi:10.1136/heartjnl-2020-317104

ORCID iD

Sanjay Rajagopalan http://orcid.org/0000-0001-66698163

\section{REFERENCES}

1 Rajagopalan S, Al-Kindi SG, Brook RD. Air pollution and cardiovascular disease: JACC state-of-the-art review. J Am Coll Cardiol 2018;72:2054-70.
2 Nicas M, Nazaroff WW, Hubbard A. Toward understanding the risk of secondary airborne infection: emission of respirable pathogens. J Occup Environ Hyg 2005;2:143-54.

3 Zayas G, Chiang MC, Wong E, et al. Cough aerosol in healthy participants: fundamental knowledge to optimize droplet-spread infectious respiratory disease management. BMC Pulm Med 2012;12:11.

4 Bin-Reza F, Lopez Chavarrias V, Nicoll A, et al. The use of masks and respirators to prevent transmission of influenza: a systematic review of the scientific evidence. Influenza Other Respir Viruses 2012;6:257-67.

5 van der Sande M, Teunis P, Sabel R. Professional and home-made face masks reduce exposure to respiratory infections among the general population. PLoS One 2008;3:e2618

6 Shakya KM, Noyes A, Kallin R, et al. Evaluating the efficacy of cloth facemasks in reducing particulate matter exposure. J Expo Sci Environ Epidemiol 2017;27:352-7.

7 Patel D, Shibata T, Wilson J, et al. Challenges in evaluating PM concentration levels, commuting exposure, and mask efficacy in reducing PM exposure in growing, urban communities in a developing country. Sci Total Environ 2016:543:416-24.

8 Sungnak W, Huang N, Bécavin C, Berg M and Network. Hlb. SARS-CoV-2 entry genes are most highly expressed in nasal goblet and iliated cells within human airways. arXiv 2003. 